\title{
Técnicas de Previsão Aplicadas para Tomada de Decisão na Minimização de Rejeitos Industriais
}

\author{
Marco Antonio Gaya de Figueiredo \\ Eng. de Processo da Divisão de Produtos (DIPROD) \\ Centro de Pesquisas Leopoldo M. Mello (CENPES) \\ Eng. Químico Universidade do Estado da Guanabara (UEG-1974) \\ Mestrado em Engenharia de Produção (1992).
}

\section{RESUMO}

Atualmente muitas empresas, face as modernas legislaçðes em vigor com respeito ao meio ambiente e, em decorrência da rápida evolução nos mecanismos adotados para a minimização dos rejeitos industriais, estão se defrontando com os seguintes questionamentos; como decidir pela melhor alternativa para a minimização dos rejeitos industriais; considerar apenas o aspecto econômico em termos de rentabilidade ou retomo do investimento.

Este trabalho apresenta um levantamento das diversas metodologias existentes para auxílio no processo de tomada de decisão correlacionados com esta nova realidade, enfocando o uso da técnica conhecida como "Brainstorming", para o levantamento das alternativas para a minimização dos rejeitos industriais numa planta em operação.

\footnotetext{
ABSTRACTS

Many industries are now concerned whether decision taking on industrial waste minimization strategy should be based either on methods rentabilility or investment return rate. This is mostly due to the severe requirements of modern environmental legislation, and to the consequent rapid evolution of the current methods for industrial waste minimization.

This work presents a search on the forcasting methods for industrial waste minimization, applicable to different stages of an enterprise (development, design and operation). Special emphasis is given to the "h:ainstorm technique", applied to an industrial unit in operation.
} 


\section{PRODUÇÃO}

\section{1 -Introdução}

De um modo geral sempre que defronta-se com diversas alternativas para resolver-se um problema deve-se optar por uma única solução, os meios disponiveis para decidir, de um modo geral, quase sempre induzem a "erros", seja por imprecisão na avaliação da alternativa, seja por falta de uma abordagem ampla sobre o problema ou, por uma tendência a explicarmos as prováveis decorrências da implantação da alternativas em fatos passados.

O trabalho irá abranger as diversas formas para identificação de alternativas que visem a minimização dos rejeitos industriais considerando-se uma planta em operação. Serão apresentados diversos esquemas para registro das informações geradas no processo e as varias possibilidades de manuseio do rejeito, propondo-se uma sistemática para tratar estas informações de modo a implementar-se a alternativa mais viável para minimização do rejeito gerado.

\section{2 - As Dificuldades no Processo de Tomada de Decisão}

No tempos atuais vive-se um processo onde, a cada dia, descobre-se uma maneira eficiente de aumentar o fluxo de informações. Os mecanismos de comunicação possibilitam aquisição e processamento das informações com velocidades cada vez maiores. Esta facilidade, se por um lado traz vantagens tais como intercâmbios tecnológicos maiores, por outro lado cria um processo cada vez mais complexo no mecanismo das "Decisões e Definições". A medida em que recebemos diversas informações sobre um determinado assunto, somos obrigados a efetuar previsões sobre os novos rumos de um determinado desenvolvimento e quais as novas tendências, sob o risco de sucumbirmos devido a uma previsão mal elaborada. É evidente que, em um processo onde as variáveis que influenciam nosso processo decisório sofrem as mais diversas interferências, os mecanismos que devemos adotar para o auxílio na tomada de decisões devem ser rápidos e flexíveis.

A atividade de Previsão, para ser eficaz, deve atender basicamente aos seguintes critérios:

Compreensão, discernimento e imaginação para reconhecer os avanços potenciais resultantes de algumas tendências aparentemente não relacionadas;

- Conhecimento da tendências;

- Capacidade de comunicação com planejadores e com quem tomas as decisões;

De uma maneira geral, para análise da alternativa objeto do processo de tomada de decisão, visando a base para o raciocínio estratégico; seu ponto de partida, nos posicionamos diante de problemas, tendências, acontecimentos ou situações de um todo harmonioso. Somos obrigados a interpretá-los separando e 
analisando, individualmente, os componentes um a um após o que analisamos os parâmetros para, finalmente, recompormos o problema objetivando obter o melhor conhecimento possivel.

Na restruturação, não utilizamos uma figura padrão, semelhante a análise de sistemas. Normalmente o instrumento menos linear que utilizamos é o poder da mente. Independente do grau de complexidade do problema, devemos reduzir nossa trajetória na busca da melhor alternativa, combinando uma análise racional (baseada na natureza das coisas) com a reintegração imaginosa de todos os componentes dentro de uma nova ética.

Uma representação simplificada esta forma de analisar um problema pode ser observado na Figura (1). ${ }^{(1)}$
Dentre as diversas técnicas de abordagem que possamos adotar, o método que mais se aproxima do "raciocínio natural" ou da "intuição", conforme apresentado por Harry Jones ${ }^{(2)}$, está em efetuarmos o denominado "Brainstorming", que promove uma livre fusão de diversas opiniões. Esta técnica permite o levantamento de diversos pontos os quais devem ser classificados de acordo com fatores comuns. Estes agrupamentos são ordenados em grupos que possuam um denominador comum, de modo a podermos encarar cada grupo como uma unidade separada. A Figura 2 apresenta uma visualização do processo de afunilamento da questão sobre um determinado problema.

Nesta lógica, verifica-se que a finalidade básica da previsão é reduzir o grau de incerteza, e não de eliminá-lo. Trabalha-se com dados que possuem diversos graus de precisão referentes ao passado e ao presente.

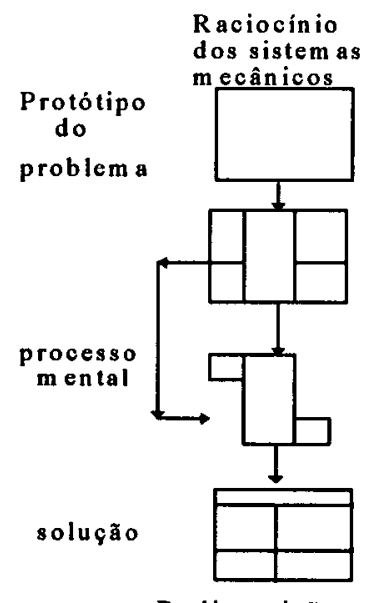

Redisposição dos sistemas

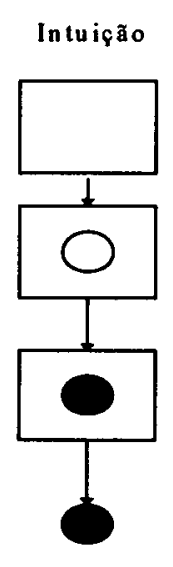

Ponto focal

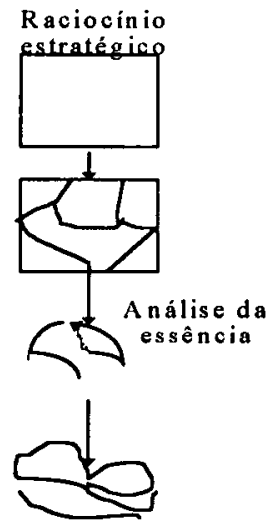

Configurą̧ão modificada

Figura 1: Três tipos de processo mental 


\section{PRODUÇÃO}

\begin{tabular}{|c|c|c|c|}
\hline Fenômeno & Agrupamento & Abstração & Determinação do método \\
$\begin{array}{c}\text { Perdas } \\
\text { Poluição }\end{array}$ & Tecnologia & Controle de mundanças & Método de análise \\
& & Nova tecnologia \\
\hline
\end{tabular}

Figura 2. $\mathrm{O}$ afunilamento da questão

\section{3 - O Processo de Priorização e Seleção de Alternativas}

Embora tenha-se respondido a todas as perguntas sobre o problema e afunilado ao máximo a questão que se apresenta, na presença de várias alternativas, qual a que melhor se adapta ao objetivo definido; como pode-se garantir, com uma pequena margem de erro, a escolha de uma determinada opção; qual a melhor forma de agrupar os parâmetros encontrados e como priorizá-los?

Para responder a estes questionamentos deve-se estabelecer uma hierarquia dentro das alternativas apresentadas, calcada em uma forte base científica visando minimizar (ao máximo) os erros de previsão.

Nos últimos tempos, a importância crescente de fatores não tecnológicos como determinantes do progresso tecnológico, particularmente as tendências sociais e financeiras tem sido mais reconhecidas. Dentre os pontos básicos que devem ser considerados para execução de um planejamento consideramos os seguintes fatores;

- Previsão dos estágios de progressos tecnológicos;

- Avaliação do custo para organização;

- Avaliação dos benefícios sociais e econômicos;

Estes fatores são justificados devido as seguintes caracteristicas;

- Restrições financeiras ao progresso tecnológico;

- Eficiência do investimento em Tecnologia ;

- Aspectos relacionados com o meio ambiente;

- Exaustão de matérias-primas;

- Modificações constantes nas legislações de controle ambiental 


\section{PRODUÇÃO}

\section{4 - Metodologias para o 5 -A Minimização de Processo de Priorização \\ Rejeitos Industriais}

Como o desenvolvimento das técnicas de previsão acompanharam todas as tendências tecnológicas, podemos classificá-las em quatro grandes grupos a saber (tabela 1).

\section{1-Situação Atual}

Dentro de um cenário abrangente podemos, basicamente, definir três grandes regras para estudar a

\begin{tabular}{|c|c|c|}
\hline Métodos & Base & Caracteristicas \\
\hline Qualitativos (2) & $\begin{array}{l}\text { Descrição } \\
\text { puramente } \\
\text { narrativa }\end{array}$ & $\begin{array}{l}\text { * Pensamentos intuitivos de qualquer espécie, } \\
\text { "Brainstorming" e estudo de situações hipotéticas } \\
\text { * Analogias históricas, biológicas e geográficas; } \\
\text { * Mapeamento contextual e modelo independente do } \\
\text { tempo; } \\
\text { * Abordagem da árvore de relevância; } \\
\text { * Análise e reconstrucão morfológicas; } \\
\text { * Análise de lacunas tipo Mendelejev; } \\
\text { * Sinais de mudanças tecnológicas e fíçaão científica }\end{array}$ \\
\hline Quantitativos & $\begin{array}{l}\text { Conceito medido } \\
\text { em termos ou } \\
\text { unidades bem } \\
\text { definidas }\end{array}$ & $\begin{array}{l}\text { As unidades devem ser, de preferência, em termos de } \\
\text { eficiênciae desempenho, todavia podem ser medidas } \\
\text { por valores econômicos como custo, antecipacão no } \\
\text { mercado etc. }\end{array}$ \\
\hline $\begin{array}{l}\text { Baseados no } \\
\text { tempo }\end{array}$ & $\begin{array}{l}\text { Nestes métodos } \\
\text { demonstra-se daqui } \\
\text { a quantos anos } \\
\text { fenômeno ocorrerá } \\
\text { e se tornará real. }\end{array}$ & $\begin{array}{l}\text { 1. Análise de séries temporais e proję̃oes de } \\
\text { dimensões fisicas simples, capacidades funcionais, } \\
\text { dimensões econômicas, demograficas e sociológicas } \\
\text { no tempo. } \\
\text { 2. Determiną̧a de curvas de séries temporais e em } \\
\text { "S". } \\
\text { 3. Curvas de aprendizado } \\
\text { 4. Relações entre duas dimensões não temporais com } \\
\text { base nos métodos quantitativos. } \\
\text { 5. Matrizes de insumos e produto e de relevância, ou } \\
\text { modelos de substituição em base temporal. }\end{array}$ \\
\hline & & 6. Modelos quantitativos \\
\hline Probalisticos & $\begin{array}{l}\text { Baseados em } \\
\text { suposições } \\
\text { relativas a } \\
\text { probabilidade }\end{array}$ & Delfi, Impactos Tranversais e Métodos dos jogos \\
\hline
\end{tabular}

Tabela 1 - Métodos de Previsāo 


\section{PRODUÇÃO}

minimização de rejeitos industriais. A primeira está relacionada com o estudo da minimização na etapa de desenvolvimento de processo, a segunda na etapa de projeto e a última a minimização dos rejeitos nas plantas já em operação.

Conforme apresentado por Ronald L.Berglund e Glenn Snyder ${ }^{(3)}$ podemos tipificar as três etapas conforme a Figura 5.

\subsection{Estudos durante a etapa de Desenvolvimento}

Na etapa de desenvolvimento de processo, as oportunidades para a redução são mais eficientemente exploradas depois deterem sido definidas as rotas para a obtenção do produto a ser estudado. Um ponto chave a ser seguido está na elaboração de um balanço de massa em torno do processo, o qual deverá ser o mais simples possivel incluindo todos os possiveis contaminantes nas matériasprimas, informações sobre degradação de produtos, catalisadores e solventes utilizados para limpezas. Terminado este balanço, os seguintes questionamentos devem ser efetuados:

- Como o resíduo é gerado ?

- Por que o resíduo é gerado ?

- O resíduo é perigoso ?

- Como seu volume poderá ser reduzido ?

- Quanto irá custar para reduzir seu volume ou toxidade?

É economicamente viável a redução do volume ou da toxidade?

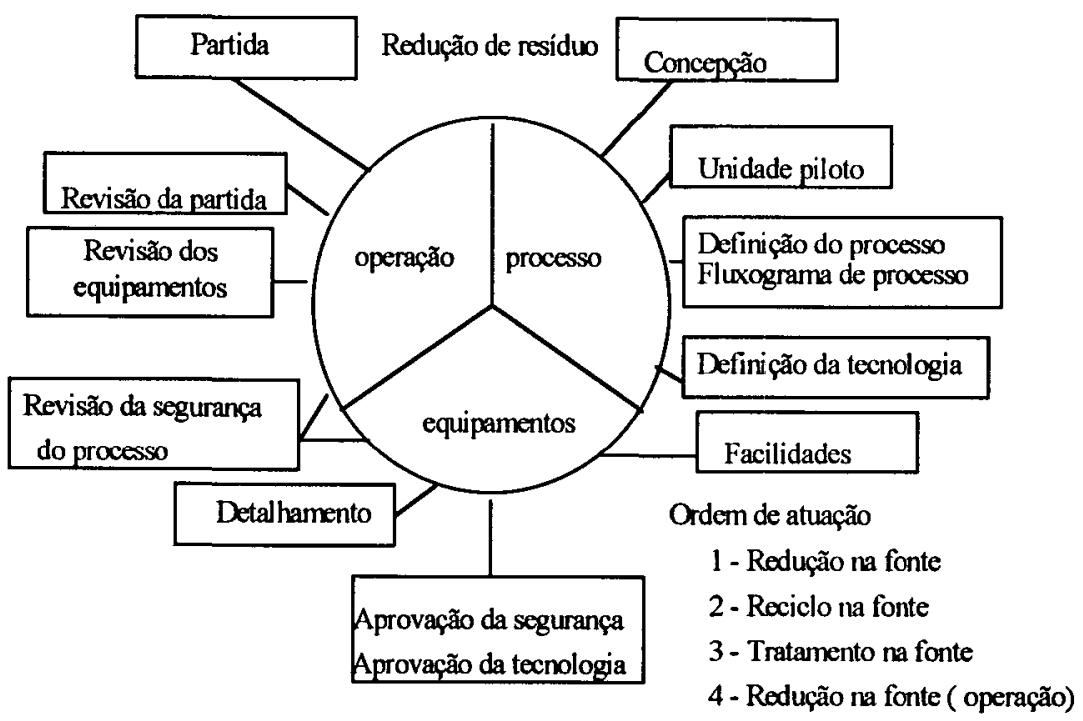

Figura 5. - Redução de rejeitos industriais e desenvolvimento 


\section{PRODUÇÃO}

A meta do pesquisador deverá ser de obter um produto com um minimo de formação de subproduto não manuseável. As modificações recomendadas nesta fase incluem: melhoramento nos controles, minimização de água ou uso de solvente, segregação de correntes ou concentração, troca de reagentes, otimização das condições de reação, melhoramentos no sistema catalítico, reciclos internos e evitar o contato entre água de produtos orgânicos.

\section{3 - Estudos durante a fase de Projeto}

A minimização dos rejeitos industriais na etapa de projeto de processo deverá manter a mesma linha. Nesta fase o grupo de engenharia deverá trabalhar dentro do seguinte questionamento:

- Como dispor os equipamentos para minimizar o gasto de energia ?

- Como otimizar o manuseio de produtos reduzindo a periodicidade das operações de limpeza dos equipamentos de processo ?

- Os equipamentos de processo geram perdas consideráveis?

- Os efluentes gerados serão segregados?

- É economicamente viável a implementação de sistemas para tratamento dos efluentes gerados?

O principal objetivo nesta fase do trabalho será o de se gerar um projeto de engenharia de processo adequado tanto as condições estabelecidas no desenvolvimento do processo, como certificar-se do atendimento ás regulamentações oficiais para implantação do projeto. A complementação da tarefa de minimização de rejeitos industriais num processo em implantação continua no período de condicionamento e testes de ré operação. Nesta etapa são efetuados os ajustes tanto nos procedimentos operacionais como nas condições de controle, visando adequar o projeto as condições definidas no desenvolvimento.

\section{4 - Estudo em unidades já existentes}

A terceira grande área para minimização de rejeitos industriais, o estudo de plantas industriais já existentes, que utilizam tecnologias cujo desenvolvimento não contemplava a minimização e sim o tratamento do rejeitos gerados. Neste caso a minimização dos rejeitos industriais, a nivel de início do levantamento das alternativas, observa a seguinte hierarquia (4). (figura a seguir)

O levantamento destas alternativas deve ser efetuado com base em uma reunião entre todos os envolvidos direta e indiretamente no processo produtivo a saber: pessoal da operação, grupo de desenvolvimento de processo e grupo de marketing pois, diferente do tratamento que, implementado na saída da unidade, a minimização exige o conhecimento de todos os aspectos relativos tanto ao 


\section{PRODUÇĀO}

\begin{tabular}{|c|c|c|c|c|c|c|}
\hline $\begin{array}{c}\text { Redução } \\
\text { na } \\
\text { fonte }\end{array}$ & $\begin{array}{c}\text { Redução } \\
\text { na } \\
\text { geração }\end{array}$ & Reciclo & Reutilização & Recuperação & Tratamento & Descarte \\
\hline \multicolumn{6}{|c|}{ Preferência de atuação } \\
\hline
\end{tabular}

processo de produção como nas formas de desuso adotadas pelos consumidores. Como exemplo o quadro (1) abaixo as possiveis formas de atuação na minimização dos rejeito em plantas já em operação ${ }^{(5)}$.
6 - Aplicação
do
"Brainstorming"
para Identificação de Alternativas para a Minimização dos Rejeitos Indústriais

\section{Quadro1}

Técnicas de minimização

\begin{tabular}{|c|c|c|}
\hline Forma de Atuação & Indústria & Técnicas \\
\hline Gerenciando o inventário & $\begin{array}{l}\text { Têxtil } \\
\text { Móveis } \\
\text { Máquinas diesel }\end{array}$ & $\begin{array}{l}\text { Revisão dos produtos quimicos } \\
\text { Fornecimento de produtos na } \\
\text { quantidade necessária } \\
\text { Separação dos produtos adquiridos }\end{array}$ \\
\hline Substituição de materiais & $\begin{array}{l}\text { Tintas } \\
\text { Fabricação de } \\
\text { impressos }\end{array}$ & $\begin{array}{l}\text { Substituição de produtos a base de } \\
\text { água por solvente } \\
\text { Substituição do pigmento a base de } \\
\text { cádmio. }\end{array}$ \\
\hline Modificą̧a de processos & Reação Quimíca & $\begin{array}{l}\text { Otimizaça das variáveis de processo } \\
\text { Otimiząão dos procedimentos de } \\
\text { carga. Eliminą̧a dos catalisadores } \\
\text { tóxicos }\end{array}$ \\
\hline Reciclo de processo & $\begin{array}{l}\text { Fabricą̧ão de } \\
\text { metais } \\
\text { Fabricą̧ão de } \\
\text { tintas } \\
\text { Produção de } \\
\text { Circuitos } \\
\text { Impressos }\end{array}$ & $\begin{array}{l}\text { Recuperação do fluido de corte por } \\
\text { centrifugąão } \\
\text { Recuperą̧ão de solvente por } \\
\text { destilação } \\
\text { Sistema de recuperação eletrolitica } \\
\text { de cobre e estanho }\end{array}$ \\
\hline
\end{tabular}




\section{PRODUÇÃO}

\section{1. - Elaboração do relatório para realização do "Brainstorming"}

A finalidade do Brainstorming, como já mencionado, é o de promover-se uma discussão ampla, com todos os técnicos envolvidos no processo produtivo, visando levantar-se todas as alternativas possiveis para "Atacar" o problema. A forma apropriada para elaborar-se esta reunião deverá atender aos seguintes requisitos:

6.2 - Levantamento detalhado do problema a ser discutido

De um modo geral, encontramos as possíveis formas conhecidas para levantamento de problemas referentes ao monitoramento e minimização dos rejeitos industriais:

- Controle das perdas de processo;

- Acompanhamento da geração de produto fora de especificação;

- Monitoramento ambiental dentro do parque fabril;

- Autos dos órgãos de fiscalização do meio ambiente;

A apresentação deverá ser a mais completa possível, visando informar todos os aspectos verificados em cada área.

Como por exemplo temos:

\section{a) Perdas de processo}

O levantamento dos dados neste controle dever conter as seguintes informações; (Quadro abaixo)

As observações devem conter, além das causas e das conseqüências, as possíveis medidas para eliminar o fato gerador.

b) Geração de produtos fora de especificação

Este acompanhamento deverá ser realizado pelo pessoal de operação e o levantamento e controle, a depender do tipo de processo., poderá ser por reação ou por turno caso o sistema reacional seja em batelada ou diariamente no caso de sistema contínuo.

Os dados, neste caso, são mais complexos pois envolvem diversas possibilidades tais como: utilização de insumos fora de especificação, problemas nos controles do sistema, "erros" operacionais. Este acompanhamento poderá ser efetuado, mediante a utilização de cartas de controle (Cartas de Shewart)

\begin{tabular}{|l|l|l|}
\hline Data & \multicolumn{1}{|c|}{ Área verificada } & \multicolumn{1}{|c|}{ Observações efetuadas } \\
\hline 1103193 & $\begin{array}{l}\text { Recebimento de } \\
\text { matéria-prima }\end{array}$ & $\begin{array}{l}\text { Rompimento de embalagens } \\
\text { gerando perda de X quilos de } \\
\text { produto e ocasionando uma } \\
\text { interrup̧̧ão nos trabal hos de Y } \\
\text { horas }\end{array}$ \\
\hline 3104193 & Área de reação & $\begin{array}{l}\text { Entupimento da linha } \\
\text { interrompendo o processo }\end{array}$ \\
\hline
\end{tabular}




\section{PRODUÇÃO}

\section{c) Monitoramento ambiental dentro do parque fabril}

O controle neste caso está relacionado aos procedimentos operacionais adotados para limpeza e manutenção dos equipamento, no manuseio dos produtos utilizados e no manuseio dos subprodutos gerados. Também permitem um "conhecimento" do nivel de poluição gerado devido a falhas no processo produtivo.

O levantamento dos dados neste caso, realizado pelos departamentos de saúde ocupacional e da segurança industrial da empresa, que realizam periodicamente um acompanhamento nas condições do ambiente fabril, verificando níveis dos prováveis poluentes na atmosfera $\mathrm{e}$ controlando possiveis contaminações com o pessoal envolvido diretamente na manipulação dos produtos químicos.

A apresentação destes dados normalmente indicam as áreas que devem ser preferencialmente estudadas e os produtos que devem ficar sob maior controle.

\section{d) Autos dos órgãos de fiscalização do meio ambiente}

As empresas são periodicamente inspecionadas pelos órgão de controle ambiental $\mathrm{e}$, no caso de não conformidade com a legislação em vigor, são lavrados autos de infrações onde são registrados os problemas observados e sugestões que para solucioná-los.

O levantamento destes dados devem conter: a data em que foi efetuada a inspeção, a ocorrência, a fonte geradora e a possivel forma de solucioná-lo.

\begin{tabular}{|c|l|l|}
\hline $\begin{array}{c}\text { Data da } \\
\text { ocorrência }\end{array}$ & Unidade inspecionada & \multicolumn{1}{|c|}{ Advertência efetuada } \\
\hline $15 / 05 / 93$ & $\begin{array}{l}\text { Sistema de } \\
\text { condicionamento de } \\
\text { insumos }\end{array}$ & $\begin{array}{l}\text { Instalar, operar e manter o } \\
\text { sistema de ventilação local, } \\
\text { exaustora e equipamento de } \\
\text { controle de poluentes }\end{array}$ \\
\hline 22109193 & $\begin{array}{l}\text { Sistema de lavagem } \\
\text { dos gases }\end{array}$ & $\begin{array}{l}\text { Reduzir geração de odor } \\
\text { característico do processo } \\
\text { produtivo }\end{array}$ \\
\hline 01102194 & $\begin{array}{l}\text { Sistema de lavagem } \\
\text { dos gases }\end{array}$ & $\begin{array}{l}\text { Avaliação da eficiência dos } \\
\text { sistemas }\end{array}$ \\
\hline
\end{tabular}




\section{PRODUÇÃO}

\section{3 - Avaliação das alternativas propostas}

Estando preparado o relatório, deverá ser distribuída uma cópia para cada participante da reunião, visando uniformizar o conhecimento sobre as possiveis fontes de geração dos rejeitos industriais e as prováveis formas encontradas para eliminá-lo ou se possível minimizá-lo. Após um período suficiente para que os técnicos tomem conhecimento do assunto, a reunião deverá ser marcada

\section{4 - Participantes da reunião}

Um "Brainstorming" não deve se restringir apenas aos chefes e especialistas nas áreas, sua função não é a de descobrir e punir culpados, a participação deverá ser o mais abrangente possível incluindo os técnicos dos laboratórios, operadores e auxiliares. A área de marketing, caso existente, deverá participar pois as alternativas apresentadas podem vir a influenciar o processo produtivo e, este departamento, deverá informar as possiveis reações dos consumidores. A condução desta reunião deverá observar os seguintes critérios:

\subsection{1- Escolha de um mediador;}

Este profissional deverá possuir um grande conhecimento do processo fabril, evitando possíveis polêmicas surgidas nos debates sobre as alternativas apresentadas e também evitando que os "especialistas" monopolizem a reunião inibindo a participação dos outros membros.

\subsection{2- Escolha de um secretário}

Todas as alternativas apresentadas no decorrer da reunião devem ser anotadas, independente de serem factiveis ou não. Esta pessoa deverá estar atenta aos debates, sem uma participação direta evitando as "interpretações" das sugestões apresentadas.

\section{7 - Selecionamento da Técnica a ser Adotada na Priorização das Alternativas}

Após o término da reunião as alternativas apresentadas deverão ser agrupadas quanto as suas características. Deverá ser realizado um questionário onde as possíveis consequeências da implantação de cada uma das alternativas deverão ser levantadas, sendo que nesta etapa não serão consideradas as impossibilidades de implantação. De posse destas informações, uma das formas que podem ser utilizadas para obter-se uma resposta rápida da hierarquização das alternativas propostas para o problema apresentado pode ser obtida efetuando-se uma análise das possíveis conseqüências para a implementação de cada alternativa, listando-as na seguinte ordem:

- facilidade de implementação;

- disponibilidade de informações técnicas para sua implementação;

- estimativa preliminar e custo para implantação da alternativa, incluindo a necessidade de mão-de-obra externa; 
- possivel interferência da solução implantada no produto final;

- flexibilidade da alternativa a ser implantada.

O responsável pela implementação do programa deverá, com base nestas informaçōes, elaborar uma planilha contendo a hierarquização proposta que será entregue aos participantes das reunião. Esta planilha deverá ser avaliada em uma outra reunião e, a alternativa considerada mais atraente para a empresa será gradualmente implantada.

Em termos atuais dentre os métodos adotados, empresas de grande porte como por exemplo a área de Pesquisa e Desenvolvimento tem adotado em alguns processos de priorização os seguintes métodos:

\section{(a) Método de DELFI}

Método utilizado para consulta a um determinado número de especialistas, com a finalidade de resolver um problema complexo em tempo reduzido. A consulta é feita através da aplicação de uma pequena série de questionários, cujas respostas são intercambiadas para permitir a interação e o consenso das opiniões desses especialistas. Criado nos Estados Unidos da América, nos anos cinqüenta, tem sido empregado para assessorar diversos tipos de tomada de decisão, principalmente aquelas em que, necessário prever situações futuras; serve também para coletar informações a custo reduzido. (b) Método desenvolvido pelo "Boston Consulting Group" (BCG)

De forma semelhante ao método DELFI, esta técnica propõe localizar um projeto dentro de um referencial definido por dois parâmetros: a coerência com a estratégia e a atividade do projeto. As diretrizes que orientam a coerência com a estratégia são estabelecidas por técnicos especialistas que compõem um comitê tecnológico.

A coerência, permite classificar o projeto em quatro níveis (muito alta coerência (A) até muito baixa coerência (D)). A atratividade, efetuada mediante atribuição de notas ( 1 a 10 ) aos indicadores técnicos, políticos, sociais $\mathrm{e}$ econômicos. As médias das notas permite classificá-los conforme uma escala onde notas de (9a 10) implicam em muito alta atratividade (A); de (6 a 8) alta atratividade (B); de (3 a 5 ) baixa atratividade $(\mathrm{C})$ e de $(0$ a 2$)$ muito baixa atratividade (D). A análise dos dois fatores (atividade e coerência com a estratégia) possibilitam estabelecer uma escala de prioridades.

\section{8 -Conclusões}

A utilização do Brainstorming no levantamento de alternativas para a solução de problemas tem auxiliado bastante $o$ andamento de diversos projetos, esta técnica permite que todos os técnicos tomem conhecimento do nível de dificuldade encontrado por um determinado grupo no desenvolvimento de uma tarefa, aumenta a integração entre os diversos segmentos da fábrica, 


\section{PRODUÇÃO}

reforçando o sentimento de trabalho em equipe.

O processo de hierarquização utilizado, baseado nos questionamentos referentes a:

- facilidade de implementação;

- disponibilidade de informações técnicas para sua implementação;

- estimativa preliminar e custo para implantação da alternativa, incluindo a necessidade de mão-de-obra externa;

- possível interferência da solução implantada no produto final;

- flexibilidade da alternativa a ser implantada.

Apresenta a facilidade de se "prever" todas as implicações na implantação de uma determinada alternativa num curto período de tempo, eliminando o risco de se investir recursos em alternativas apresentadas por especialistas, os quais nem sempre conhecem a realidade do "chão-de-fábrica" $\mathrm{e}$ por vezes impões rotas custosas, pouco flexíveis e de baixa eficiência.

Recebido em: 22/04/97

Aceito em: 14/03/98

Publicado em: 27/07/98
2. Jones, H., Twiss, B.C., Previsão Tecnológica para Decisões de Planejamento,Zahar Editores, 1986.

3. B e r g $1 \mathrm{u} \mathrm{n} \mathrm{d,} \mathrm{R.} \mathrm{L} \mathrm{.,}$ Snyder,G.E.,Waste Minimization: The Sooner the Better. Chemtech ,p.740 746, Dec, 1990.

4. Wentz, C.A, Chiu, S.Y, Habegger, L.J et al., Design of Tracking System for Hazardous Waste Minimization. Enviromental Progress, v. 7, n. 3, p. 155 - 161, ago. 1988.

5. Freeman, H.M,Hazardous Waste Minimization, JAPAC, v. 38,n. 1 , p. $59-61$, jan. 1988.

\section{Agradecimentos}

A finalização deste trabalho foi possivel mediante a colaboração dos companheiros Maria Cristina Brum e Dellyo Ricardodos S. Alvares aos quais o autor deseja expressar os sinceros agradecimentos.

\section{9-Referências Bibliográficas}

1. Ohmae,K., O Estrategista em Ação. A Arte Japonesa de Negociar. Pioneira Editores, 1985. 